\title{
Web Annotation and Threaded Forum: How Did Learners Use the Two Environments in an Online Discussion?
}

\author{
Yanyan Sun \\ Ohio University, \\ Athens, Ohio, U.S.A
}

ys162210@ohio.edu

\author{
Fei Gao \\ Bowling Green State \\ University, \\ Bowling Green, Ohio, U.S.A \\ gaof@bgsu.edu
}

\section{Executive Summary}

Web annotation is a Web 2.0 technology that allows learners to work collaboratively on web pages or electronic documents. This study explored the use of Web annotation as an online discussion tool by comparing it to a traditional threaded discussion forum. Ten graduate students participated in the study. Participants had access to both a Web annotation tool and a threaded forum when having discussion on a given topic and were free to use either tool or both to post their comments. A case study method was adopted. The analysis of participant posts and participant survey responses showed that both the threaded forum and the Web annotation tool successfully supported interactions and knowledge construction during the online discussion. The Web annotation tool had advantages in locating specific information on the websites and making content-specific discussions, and the discussion forum was more suitable for posting summarized comments. While participants were more likely to offer alternative or complementary views in the discussion forum, self-reflection was the major type of knowledge construction behavior when participants used the Web annotation tool.

Keywords: Web Annotation, collaborative learning, higher education, online discussion environments

\section{Introduction}

Web annotation is a Web 2.0 technology that allows learners to insert notes to web pages or electronic documents. Compared to the traditional paper-based annotations, Web annotation has two key advantages: (a) learners can access annotations from any computer and (b) learners can share the annotations with others who have access to the same materials (Glover, Xu, \& Hardaker,

Material published as part of this publication, either on-line or in print, is copyrighted by the Informing Science Institute. Permission to make digital or paper copy of part or all of these works for personal or classroom use is granted without fee provided that the copies are not made or distributed for profit or commercial advantage AND that copies 1) bear this notice in full and 2) give the full citation on the first page. It is permissible to abstract these works so long as credit is given. To copy in all other cases or to republish or to post on a server or to redistribute to lists requires specific permission and payment of a fee. Contact Publisher@InformingScience.org to request redistribution permission.
2007). The collaborative nature of Web annotation makes it a platform for sharing information and promoting interactions among group members. Thus, Web annotation has been increasingly used for collaborative learning in classrooms.

Recently, with the growing demand for online collaborative learning and the increasing use of online annotation tools, studies have been conducted to 
explore the potential of using Web annotation as a collaborative tool to promote learners' performance in various educational settings (Hwang, Wang, \& Sharples, 2007; Johnson, Archibald, \& Tenenbaum, 2010; Lin \& Tsai, 2011; Mendenhall \& Johnson, 2010; Nokelainen, Miettinen, Kurhila, Floréen, \& Tirri, 2005; Su, Yang, Hwang, \& Zhang, 2010; Wang, 2010; Wolfe, 2008; Yang, Chen, \& Shao, 2004; Yang, Zhang, Su, \& Tsai, 2011; Yeh \& Lo, 2009). Little research, however, has compared the effectiveness of Web annotation in promoting collaborative learning with that of other collaborative tools. Instead of measuring the impact of Web annotation-based activities on learners' performance, the purpose of this study is to explore the use of Web annotation as an online collaborative reading and discussion environment. This study examines students' perceived attitudes towards their use of a Web annotation tool and a threaded discussion forum and offers insights on using Web annotation as a collaborative discussion tool.

This paper is structured as follows: a literature review section that provides a theoretical background; a method section that describes the setting and the methodology; a results section that presents the findings; a discussion section on the results; a section for pedagogical implications for practice; a section for limitations and future study; and a conclusion section that presents the significance of the study.

\section{Literature Review}

\section{Theoretical Framework: Social Constructivism}

Social constructivists believe that intelligence development is "a dialogic process involving persons-in-conversation, and learning is seen as the process by which individuals are introduced to a culture by more skilled members" (Driver, Asoko, Leach, Mortimer, \& Scott, 1994, p. 7). From social constructivists' perspectives, less skilled members in a community are able to construct knowledge with the scaffolding from more skilled members and internalize it when socially engaged (Driver et al., 1994).

With the development of technologies, the uses of digital learning environments are increasing rapidly. Social constructivism has been adopted by many researchers to ensure the best practice of online learning (Huang, 2002; Merriam, Caffarella, \& Baumgartner, 2007) and to design digital learning environments (Cornelius, Gordon, \& Ackland, 2011; Neo \& Neo, 2009). Compared to traditional learning environments, the adoption of social constructivism in online learning has many challenges, one of which is the isolation of learners (Huang, 2002; Merriam et al., 2007). In online learning environments, learners are geographically isolated, which makes it hard to support social interactions among them. Thus, a number of studies have focused on the successful adoption of social constructivism in online learning. In Huang's (2002) study, she proposed to enhance social interactions among learners and improve learners' achievements in online environments by fostering interactive learning, collaborative learning, and authentic learning. Bryceson's (2007) study examined five college-level Internet delivered courses between 2001 and 2005 by looking at 340 students' evaluations. The result indicated that students from different programs all perceived that socialization components in course management system were important to support a good online learning experience.

Similar to other collaborative digital learning activities, the interaction among learners is an essential part of the learning process during online discussions. Social constructivism, therefore, was adopted as the theoretical framework for this particular study because of the collaborative and interactive nature of the activities supported by Web annotation tools and threaded forums. With the social constructivist framework, we attempt to understand (1) how social interaction among learners is supported with different online discussion environments; (2) the nature of such interaction; and (3) how students perceive their learning in different discussion environments. 


\section{From Annotation to Web Annotation}

Making annotations by marking or highlighting important information on a paper-based document and/or adding information to it is a commonly used learning technique (Glover et al., 2007). By examining more than 150 used academic textbooks of college students, Marshall $(1997,1998)$ found that college students used various forms of annotation to assist their learning, ranging from highlighting key words to adding relational notes on the margins. The self-reported survey results from Ovsiannikov, Arbib, and McNeill's (1999) study showed that highlighting key parts of materials for later review and writing on the margins to record thoughts were top two forms of annotation used by college students when reading academic-related materials. In the survey, students reported that their four primary uses of annotation were to remember, to think, to clarify, and to share.

Although annotation is a common learning technique, its effectiveness in assisting learning is unproven by the existing research. Little evidence indicated that using highlighting and underlining alone promoted students' performance. Dunlosky and his colleagues (2013) evaluated the effectiveness of ten major forms of learning technique. In their report, highlighting and underlining were rated as technique of low utility. According to their review of previous empirical studies, little evidence showed highlighting and underlining had a positive effect on promoting students' performance. The effectiveness of writing notes on the margins, however, has not been thoroughly studied in previous research.

The growth in the use of Web-based learning materials challenges the use of traditional paperbased annotations. To meet the needs of learners who use Web-based learning materials, new tools that allow learners to take annotations online have emerged. While Web annotation tools allow learners to highlight, underline and add notes to Web-based materials, they also allow learners to share their annotation online with others and receive feedback. Compared to paperbased annotations, Web annotation tools provide new possible ways of learning collaboratively on Web-based materials. While the literature shows no evidence that paper-based annotations have positive effects on learning (Dunlosky et al., 2013), researchers are exploring whether the collaborative feature of Web annotation tools helps to promote teaching and learning.

\section{Teaching and Learning with Web Annotation Tools}

Researchers have examined the educational use of Web annotation tools to determine their values in promoting teaching and learning. Evidence shows that Web annotation tools can enhance collaborative learning in various learning settings.

Hwang, Wang, and Sharples (2007), for example, examined the effects of collaborative annotating Web documents on college student learning in four different learning scenarios. In the study, participants were divided into an experimental group and a control group. The experimental group went through four learning scenarios using a Web annotation tool, which included (a) the individual annotation scenario, (b) the group annotation sharing scenario, (c) the full class annotation sharing scenario, (d) and the full class sharing scenario for final exam, while the control group had three individual reading scenarios and one individual reading scenario for final exam without the Web annotation tool. The result from independent t-test indicated that students who used a Web annotation tool had better performances than those who did not in most learning scenarios except for the final exam scenarios. In the final exam scenarios, there was no significant difference between the experiment group and control group because of "the ceiling effect due to the high motivation to study for final exams" (Hwang et al., 2007, p. 697). The conclusion was supported by Su, Yang, Hwang, and Zhang's (2010) study, in which researchers conducted a quasi-experiment to examine students' performance in five collaborative learning scenarios when a Web annotation tool was used in a college-level introductory course on computer science. The 
experimental group used a Web annotation tool to have three regular group sharing learning scenarios and two group sharing learning scenarios for exams. The control group had three regular individual reading learning scenarios and two individual reading scenarios for exams without any Web annotation tool. Similarly, the learning achievements of the experimental group were significantly higher than the control group in the learning scenarios other than the exam scenarios and the first scenario. The authors suggested that the lack of significant difference between the two groups in the first scenario was because of students' unfamiliarity with the Web annotation tool.

Studies on Web annotation's effectiveness have also been conducted in different subject areas. Lin and Tsai (2011) examined the effectiveness of social bookmarking in supporting mutual exchange of information in collective information searching. Yeh and Lo (2009) measured the effectiveness of the online annotation on error correction in English as a Foreign Language (EFL) writing using an online corrective feedback and error analysis system. The results of these studies all showed that Web annotation tools had a positive effect on students' performance.

In addition, the use of Web annotation has impacts on different types of learning outcomes. Johnson, Archibald, and Tenenbaum (2010) examined the potential of a social annotation tool, Social Annotation Model-Learning System (SAM-LS), in improving college students' reading comprehension, meta-cognition, and critical thinking. Two studies were conducted. The first study was designed to measure the effect of four different highlighting and annotation practices. Four groups of students who enrolled in a college level French course served as experimental groups and used SAM-LS in reading activities. Another group of students who enrolled in the same course served as control group and did the reading activities without SAM-LS. The results showed no significant difference on the three learning outcomes between the four SAM-LS groups and a control group. The author suggested that the possible reasons could be the lack of exposure time to SAM-LS intervention and the lack of time to learn how to use SAM-LS. The second study used a between-subjects methodology with different instructional methods. The results revealed that in experimental groups, students' achievements were better in reading comprehension and meta-cognitive dimension, but there was no significant difference in critical thinking. The lack of significant results in the first study suggested that educators should be careful with the design of Web annotation-based learning activities and should consider multiple factors to make sure that the learning outcomes would not be affected by external factors such as the unfamiliarity with the technology. The effectiveness of SAM-LS was also examined by Mendenhall and Johnson (2010), who tried to determine whether there was a change in reading comprehension, critical thinking and meta-cognition skills with the use of different instructional strategies in SAM-LS. The results showed that there was no significant difference in reading comprehension, critical thinking or meta-cognition skills between the experimental groups with different instructional strategies and a control group. However, the change in critical thinking was greater than the changes in reading comprehension and meta-cognition skills. The results of these studies indicated that Web annotation tools had different impacts on different types of learning outcomes.

\section{Web Annotation as a Collaborative Discussion Tool}

Research suggests that Web annotation shared by learners can stimulate discussions on learning materials (Glover et al, 2007; Kappe \& Maurer, 1994; Koivunen \& Swick, 2001). The collaborative nature of Web annotation makes it a promising tool to support discussions over online readings. It allows users to comment on each other's annotation posts and all the annotation posts are linked back to specific places on webpages. However, most research on collaborative Web annotation explored its potential to improve students' learning. Few studies have investigated the educational potential of using Web annotation to foster online discussion. As a commonly used instructional activity, online discussions support a social constructivist model of learning, and allow 
learners to negotiate and construct meaning collaboratively in a dialogic process (Jonassen, 1990; Kanuka \& Anderson, 1998). As Web annotation allows to-the-point discussions, it might support particular types of interaction that are lacking in discussions afforded by traditional threaded discussion forums. In this paper, therefore, Web annotation was used as a collaborative discussion tool in combination with a discussion forum to support an online discussion. How participants used the two environments and the nature of discussion in both environments was examined.

\section{Method}

Diigo (www.diigo.com), a Web 2.0 social annotation tool, was used in this study. After creating a free Diigo account and installing a toolbar, users can make Web annotation by highlighting and adding floating sticky notes on a web page (Figure 1). All the web annotations can be shared within a group of users. In the study, the following research questions were addressed: When participants used Web annotation and a threaded discussion forum for an online discussion,

1. How did they make decisions on which environment to use?

2. How did they perceive their discussion experience in each environment?

3. What was the nature of discussions in each environment?

4. How did participants interact differently when constructing knowledge collaboratively?

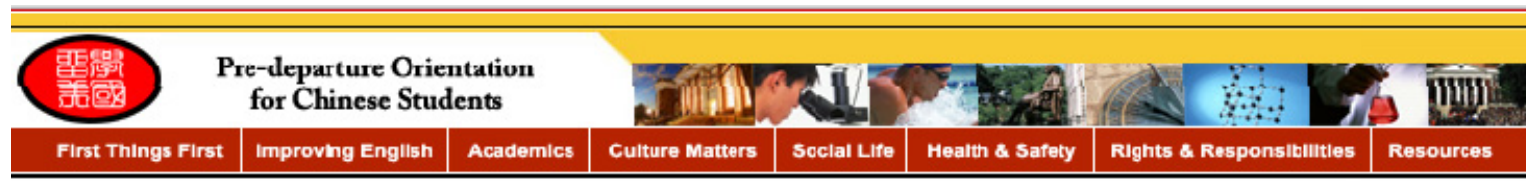

CHINESE IDEAS NOT PREVALENT IN AMERICA

To understand about cultural ciffererces, it helps to view "culture" as an iceberq. Most of an iceberg is invible, below the water level. Only a small part can be seen.

Only a small part of "culture" is open to view. We can see how people act and we can hear what they say. We may understand or misunderstand what we see and hear, but we can see and hear it.

But what people do and say is based on assumptions and values that are nvisible, below the level of the water. The behavior is based on the assumptions and values, just a: $\mathrm{d}$ Add Sticky Note

The bs EDCT 793R ifil

on ass In China people don't usually question rules, but they do

under believe that rules only work for a certain group of people in a

out of ccrtain circumstencc. ^e long as you find "a way" to get out

The $\mathrm{Cl}$ of that grcup and circumstance, you can just icnore the

cultur: rues...

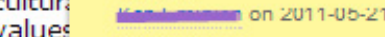

differe ECCT 793R

intera So if a rule applies to production workers and you were or are going to be a farmer then the rule might nct apply?

- $2011-05-21$

- 8 iLCT 793R 而

- $\quad \boldsymbol{y}_{\mathrm{I}}$ No really. What I meant was that some people in Chira believed that rules only applied to common people. If other-s based know about or seem wrong or

rent. The Chinese ssumptions and l iceberg. Thes

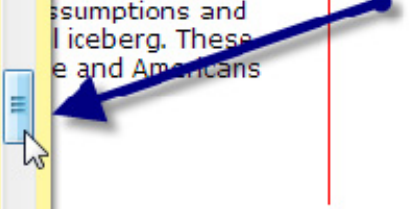

cul:ure matters Will I have "cultural shock"? What is Americon culture? Differences between Chirese \&. American culture Chinese ideas

How to adiust? Uulz for chapter 4

Floating Sticky Notes on a Webpage
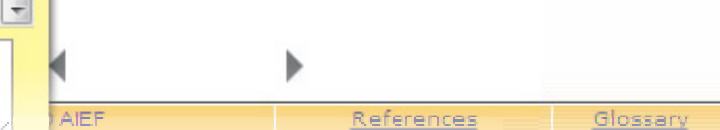

Figure 1. Diigo Floating Sticky Notes on a Webpage

A case study was conducted to investigate students' experience and participation when having discussions via a Web annotation tool and a discussion forum. More specifically, content analysis was used to analyze the nature of discussions in the two online discussion environments. In addition, a survey was administered to investigate students' perceptions on their learning experience. 


\section{Participants}

Participants in this study were ten graduate students majoring in instructional technology who enrolled in a doctoral course on technology and cognition. There were seven females and three males, and the age range was 25 to 55. Six of the participants were native English speakers while the other four spoke English as their second language. Six of them identified themselves as intermediate technology users and four of them as experts.

\section{Procedures}

A week before the study, the participants went through a tutorial on how to use Diigo and practiced creating sticky notes in class. During the study, the participants explored the official sites of the U.S. government (http://www.usa.gov/) and the Chinese government (http://www.gov.cn/english/) and then had discussions related to cultural differences using the following prompts:

1. Please locate at least one element in http://www.usa.gov/ that you think best presents the value of American culture and explain your reasons.

2. Please locate at least one element in http://www.gov.cn/english/ that you think best presents the value of Chinese culture and explain your reasons.

3. Based on the materials, discussions on Q1 \& 2, and your own experience, please list three major cultural differences between China and the U.S. and explain them.

The discussion was off-class and lasted a week. In the discussion, the participants had access to both the Diigo sticky notes and a threaded discussion forum and were free to choose either tool or both to post their responses. Each participant was required to post at least one response to each discussion question and reply to others' posts at least once during the discussion. However, students' contributions to the discussion were not graded. A questionnaire was conducted at the end of the study asking participants' attitudes towards using different tools.

\section{Measures}

To examine the different nature of discussions in a Web annotation environment and a discussion forum, all the postings in Diigo sticky notes and the threaded discussion forum were coded to identify (1) focus and (2) types of knowledge construction processes.

Focus. To determine the focus, each posting was coded into one of these three categories: (1) general comment: comment not closely related to the specific information on the websites, but related to the topics in general; (2) page comment: comment closely related to a specific page on the websites; and (3) specific section comment: comment closely related to a specific section on a specific page of the websites.

Interaction and Knowledge Construction. To measure the interactions among learners in the two environments, we counted the numbers of initial posts and replies. Gao's (2013) coding scheme was adopted to identify knowledge construction processes taking place in both environments. This particular coding scheme was developed based on Pena-Shaff and Nicholls's (2004) coding scheme and Dillenbourg and Schneider's (1995) work on collaborative learning. The coding scheme was chosen because it captures the processes of knowledge construction and learning in such collaborative online discussion activities (Gao, 2013). Six types of knowledge construction behaviors in the coding scheme are self-reflection, elaboration/clarification, alternative/complementary proposal, internalization/appropriation, conflict/disagreement and support (Table 1). 
Table 1. Coding Scheme of Knowledge Construction Processes (Gao, 2013)

\begin{tabular}{ll}
\hline Categories & Behaviors \\
\hline Self-Reflection & $\begin{array}{l}\text { Learners reflect on and interpret what they have learned } \\
\text { from the text (most of the initial posts will be coded as } \\
\text { self-reflection). }\end{array}$ \\
$\begin{array}{l}\text { Learners build upon an existing comment by adding sup- } \\
\text { porting examples and justification (without proposing new } \\
\text { perspectives/views/ideas). }\end{array}$ \\
$\begin{array}{l}\text { Learners offer complementary or alternative views or per- } \\
\text { spectives. }\end{array}$ \\
$\begin{array}{l}\text { Learners paraphrase the concepts/ideas in their classmates' } \\
\text { Complementary Proposal } \\
\text { Internalization/Appropriation } \\
\text { out contributing new ideas. }\end{array}$ \\
$\begin{array}{l}\text { Learners show disagreement or conflicting opinions. } \\
\text { Disagreement }\end{array}$ \\
Support & $\begin{array}{l}\text { Learner agrees with the text or other people's ideas with- } \\
\text { out further explanation, establishes rapport, or shares feel- } \\
\text { ings }\end{array}$ \\
\hline
\end{tabular}

Participant Survey. In addition, the survey results were analyzed to explore students' perceptions on their learning experience in two different environments. The survey consisted of 15 questions (See Appendix A). The short answer questions in the first part asked participants about their general experience in the Web annotation environment, where they posted their responses, and why they made the choice of which environment to post in. The following eight items asked participants to rate and compare their experience in the two environments in terms of usability and engagement. A five-point Likert scale was used for the rating, where strongly disagree $=1$ and strongly agree $=5$. Participants were also asked to explain their ratings and share their suggestions on improving the learning experience in the Web annotation environment. Participants' responses to open-ended questions were reviewed and used as an additional data source to support and/or explain the themes identified from the analysis of participants' postings and Likert-scale questions

\section{Results}

\section{Choice of Environments}

In the study, the participants were provided with both a Web annotation tool (Diigo sticky notes) and a threaded discussion forum in the discussion activity and were able to use either tool or both to post their responses based on their needs or preferences. The analysis of postings showed that one participant had posted all responses using Diigo sticky and one participant had posted all responses in the threaded discussion forum. The rest eight participants chose to post responses to different questions in different environments (Table 2). 
Table 2. Demographic Information of Participants and Choice of Environment

\begin{tabular}{|c|c|c|c|c|}
\hline Participants & Gender & Age & $\begin{array}{l}\text { Technology } \\
\text { Proficiency }\end{array}$ & Choice of Environment \\
\hline A & Female & 45 and above & Expert & All in Diigo \\
\hline B & Male & $25-30$ & Expert & All in discussion forum \\
\hline \multirow[t]{2}{*}{$\mathrm{C}$} & Male & $20-25$ & Intermediate & $74 \%$ in Diigo \\
\hline & & & & $26 \%$ in discussion forum \\
\hline \multirow[t]{2}{*}{$\mathrm{D}$} & Female & $20-25$ & Intermediate & $43 \%$ in Diigo \\
\hline & & & & $57 \%$ in discussion forum \\
\hline \multirow[t]{2}{*}{$\mathrm{E}$} & Male & 45 and above & Intermediate & $22 \%$ in Diigo \\
\hline & & & & $78 \%$ in discussion forum \\
\hline \multirow[t]{2}{*}{$\mathrm{F}$} & Female & $20-25$ & Expert & $64 \%$ in Diigo \\
\hline & & & & $36 \%$ in discussion forum \\
\hline \multirow[t]{2}{*}{ G } & Female & $26-30$ & Intermediate & $45 \%$ in Diigo \\
\hline & & & & $55 \%$ in discussion forum \\
\hline \multirow[t]{2}{*}{$\mathrm{H}$} & Female & $31-35$ & Intermediate & $75 \%$ in Diigo \\
\hline & & & & $25 \%$ in discussion forum \\
\hline \multirow[t]{2}{*}{ I } & Female & $20-25$ & Intermediate & $19 \%$ in Diigo \\
\hline & & & & $81 \%$ in discussion forum \\
\hline \multirow[t]{2}{*}{$\mathrm{J}$} & Female & $26-30$ & Expert & $43 \%$ in Diigo \\
\hline & & & & $57 \%$ in discussion forum \\
\hline
\end{tabular}

Based on participants' responses to the survey, the primary reason for choosing one environment over the other was the difference in their affordances. Four participants pointed out that while Diigo sticky notes were much easier to use when exploring and locating information on the websites, the threaded discussion forum worked better for reflecting on and summarizing ideas. Participant D stated, "If I find something useful and interesting on the webpage, I will use sticky notes. Discussion forum is a good place to reflect and summarize, while sticky notes are good for exploration."

The focus of questions also had an impact on participants' choice of environments, as some believed that one environment can better facilitate certain learning processes than the other. Participant G stated that "I used sticky notes to locate the sections related to question 1 while posted my discussions in discussion forum, because the discussion forum has more space for longer posts."

Participant B chose to post on the discussion forum only because he was more familiar with it. Diigo sticky notes were new to him, which made the discussion forum an easier choice: "I like sticky notes. But I think I would rather use the discussion forum because it is simple, visible and 
easy to do. People can see where to reply to it. The sticky note is hidden and sometimes we don't know how to reply to it."

In addition, Participant $C$ said that he chose to post in both environments because he wanted to try the both options: "I don't know that I'll be able to speak for every situation, but I made the above decisions because I wanted to try each option."

In general, participants reported that the primary reason for them to decide where to post was the different functionality of the tools. The focus of discussion questions was another factor related to learners' choice. Some participants reported that the familiarity with the tools had an impact on their decisions.

\section{Perceived discussion experience}

Participants were asked to rate their learning experience in different discussion environments using a five-point Likert scale. The results showed that participants had different attitudes towards Diigo sticky notes and the threaded discussion forum in terms of usability and engagement.

Usability. As presented in Table 3, students rated Diigo sticky notes higher than the discussion forum in terms of making it easier to pay attention to specific information in the web Also, compared to the discussion forum, students rated Diigo sticky notes higher for making it easier to connect a specific element in the Web to discussion. However, their ratings on the discussion forum were higher than Diigo sticky notes when it comes to how easy it is to exchange ideas or opinions with classmates and how easy it is to revise the understanding on the topics. It is worth noting that, though the comparison suggests tendencies of participant ratings, due to the small number of participants, we didn't run any statistical tests to find out whether the differences in the ratings are statistically significant. However, we calculated effect size (Cohen's d) for each item to provide a view of the magnitude of differences between the ratings in the two environments. According to Cohen (1992), 0.20 is considered as a small effect size, 0.50 as a medium effect size and 0.80 as a large effect size.

Table 3. Means (and Standard Deviations) of Student Ratings on Functions (n=10)

\begin{tabular}{llll}
\hline & Diigo & Discussion forum & Cohen's d \\
\hline $\begin{array}{l}\text { Made it easy to read everyone } \\
\text { else's posts. }\end{array}$ & $3.2(1.4)$ & $3.4(1.4)$ & -0.15 \\
$\begin{array}{l}\text { Made it easy to pay attention to } \\
\text { specific information in the Web }\end{array}$ & $4.3(1.0)$ & $3.4(1.3)$ & 0.80 \\
$\begin{array}{l}\text { Made it easy to connect a spe- } \\
\text { cific element in the Web to your } \\
\text { discussion. }\end{array}$ & $3.9(1.2)$ & $3.1(1.1)$ & 0.69 \\
$\begin{array}{l}\text { Made it easy to revise your un- } \\
\text { derstanding of the topics. }\end{array}$ & $3.6(0.8)$ & $4.0(0.7)$ & -0.53 \\
$\begin{array}{l}\text { Made it easy to exchange ideas } \\
\text { or opinions with your class- } \\
\text { mates }\end{array}$ & $3.8(0.9)$ & $4.4(0.7)$ & -0.73 \\
\hline
\end{tabular}

Many participants commented on the location-dependent nature of Diigo sticky notes: "Sticky notes are location-dependent. I think it's very useful and more inclined to trigger deep thinking" (Participant F); "The sticky notes were novel and could be used to comment directly on a specific 
item, so this was useful. The discussion forum was just a standard message board and didn't offer much benefit beyond what other discussion boards do" (Participant J).

Engagement. The rating showed that participants felt slightly more actively engaged using Diigo sticky notes than in the discussion forum (see Table 4). The Diigo sticky notes had a higher rating on making participants more willing to participate than the discussion forum. Participants also perceived that it was much more fun to use Diigo sticky notes than using the discussion forum.

Table 4. Means (and Standard Deviations) of Student Ratings on Engagement $(n=10)$

\begin{tabular}{lccc}
\hline & Diigo & Discussion forum & Cohen's d \\
\hline $\begin{array}{l}\text { Made me more willing to } \\
\text { participate in the discussion }\end{array}$ & $4.0(1.0)$ & $3.1(1.2)$ & 0.80 \\
Was fun & $4.1(1.00)$ & $3.0(0.9)$ & 1.14 \\
Actively engaged me & $3.9(1.1)$ & $3.1(1.2)$ & 0.69 \\
\hline
\end{tabular}

In the open-ended questions, participants expressed similar ideas of having fun and being actively engaged when using Diigo sticky notes: "Diigo sticky notes was definitely more fun and it was easier to make a quick comment on someone else's post" (Participant F); "Diigo sticky notes is new to me and I think it's very useful; thus I am more engaged and more willing to participate" (Participant F); "I think the sticky notes were fun because it was like getting a little surprise to open a web page and see a sticky note waiting to be opened" (Participant A).

\section{Nature of Discussion and Interaction}

Quantity of Posts. The analysis of all discussions showed that there were more posts in Diigo sticky notes. As presented in Table 5, in total, there were 34 posts in Diigo sticky notes and 23 posts in the discussion forum. However, in the discussion forum the posts were longer. To make the results reflect the actual post length, we checked all the posts and found that there were no replicate of webpage contents in any post. In the discussion forum, the average words per post were 142, which were 106 words more than the average number of words in Diigo sticky notes. This result was consistent with the survey results showing that participants were more willing to participate using sticky notes while the discussion forum had a larger number of average words per posts.

Table 5. The Number and the Length of Posts in Two Environments

\begin{tabular}{lll}
\hline Environment & Number of posts & $\begin{array}{l}\text { Average words per post } \\
\text { (Standard Deviation) }\end{array}$ \\
\hline Diigo sticky notes & 34 & $36(42)$ \\
Discussion forum & 23 & $142(141)$ \\
\hline
\end{tabular}

Focus. All the discussion posts were coded into one of the three categories based on their focus: (1) general comment: a comment not closely related to the specific information on the websites, but related to the topics in general; (2) page comment: a comment closely related to a specific page on the websites; and (3) specific section comment: a comment closely related to a specific section on a specific page of the websites. 
Table 6. The Focus of Posts in Two Environments

\begin{tabular}{lcc}
\hline & Sticky notes $(\mathrm{N}=34)$ & Discussion forum $(\mathrm{N}=23)$ \\
\hline General comment & $9(27 \%)$ & $20(87 \%)$ \\
Page comment & $10(29 . \%)$ & $3(13 \%)$ \\
Specific section comment & $15(44 \%)$ & $0(0 \%)$
\end{tabular}

Note. $\mathrm{df}=2 ; \operatorname{sig}<.001$

Table 6 showed the proportions of the types of posts in sticky notes and the discussion forum. A Chi-square test was conducted to provide a sense of the magnitude of the difference between the two environments and the significance level was less than $.001(\mathrm{df}=2)$, indicating that the proportions of post types were significantly different in the two environments. In the discussion forum, the most frequently used comment type was general comment. Of all the posts, $87 \%$ were related to the topic in general. No posts were closely related to a specific section on a specific page of the websites, and only $13 \%$ of the posts were closely related to a specific page on the websites. However, in sticky notes, all three comment types were observed. $27 \%$ of the posts were general comment, $29 \%$ of the posts were page comment and the rest of $44 \%$ were specific section comments.

Interaction and Knowledge Construction. As presented in Table 7, there were 24 initial posts and 10 replies in Diigo sticky notes. The average number of replies per post was $0.42(\mathrm{SD}=$ 1.06). In the discussion forum, there were 11 initial posts and 12 replies. The average number of replies per post was $1.09(\mathrm{SD}=0.65)$. In Diigo sticky notes, $53 \%$ of the initial posts had no reply while in the discussion forum the number was $26 \%$.

Table 7. Interactions in Two Environments

\begin{tabular}{lll}
\hline & Diigo sticky notes $(\mathrm{N}=34)$ & Discussion forum(N=23) \\
\hline Initial posts & $24(71 \%)$ & $11(48 \%)$ \\
Replies & $10(29 \%)$ & $12(52 \%)$ \\
Initial posts with no reply & $18(53 \%)$ & $6(26 \%)$ \\
$\begin{array}{l}\text { Average number of replies per } \\
\text { post (Standard deviation) }\end{array}$ & $0.42(1.06)$ & $1.09(0.65)$ \\
\hline
\end{tabular}

The types of knowledge construction behaviors that took place in both environments were presented in Table 8. It showed that the major types of knowledge construction in both environments were self-reflection and alternative/complementary proposal. However, compared to the discussion forum, the percentage of self-reflection was higher in Diigo sticky notes. This is probably because Diigo offered participants with more opportunities to frequently jot down their reflections and interpretations when they were exploring the ideas in the text. The percentage of alternative/complementary proposal in the discussion forum was higher than in Diigg sticky notes. The results suggested that participants might be more likely to offer complementary or alternative views or perspectives in the discussion forum, which was consistent with the survey result where participants felt that they were more likely to revise their understandings when having discussions in the discussion forum than with sticky notes. 
Table 8. The Knowledge Constructions of Posts in Two Environments

\begin{tabular}{lll}
\hline & $\begin{array}{l}\text { Diigo sticky notes } \\
(\mathrm{N}=34)\end{array}$ & Discussion forum (N=23) \\
\hline Self-Reflection & $23(68 \%)$ & $12(52 \%)$ \\
Alternative/Complementary Proposal & $8(23 \%)$ & $10(44 \%)$ \\
Conflict/Disagreement & $2(6 \%)$ & $0 \quad(0 \%)$ \\
Internalization/Appropriation & $1 \quad(3 \%)$ & $0 \quad(0 \%)$ \\
Elaboration/Clarification & $0(0 \%)$ & $1 \quad(4 \%)$ \\
Support & $0(0 \%)$ & $0(0 \%)$ \\
\hline
\end{tabular}

\section{Discussion}

By examining a Web annotation tool, Diigo, and the threaded discussion forum as online discussion tools, the study showed several findings. Both the threaded discussion forum and Web annotation had their own affordances in terms of supporting interactions in online discussions. Web annotation had advantages in locating specific information on the websites and linking the websites to discussion; the discussion forum was more suitable for posting summarized discussions. For participants, the primary reason for tool selection was the distinctive functions of two environments. When the discussion questions were related to locating specific information on the websites, participants tended to use the Web annotation tool. The higher average words per post in the discussion forum indicated that participants might be more likely to post longer posts in the forum.

The different interaction patterns supported by Diigo and the discussion forum influenced the learning taking place in the two environments. The discussion forum was reported as easier for participants to exchange ideas and to revise their understanding of discussion topics than Web annotation. While participants were more likely to offer alternative/complementary views in the discussion forum, self-reflection was the major type of knowledge construction behavior when participants used Web annotation. Our analysis revealed that the posts in the discussion forum received a greater number of replies on average than those in Diigo. Although there were more posts in the Diigo sticky notes, more than half of the initial posts had no reply. A possible reason was that the posts in Diigo were spread out on the different locations on webpages. In this study, participants were asked to explore the official sites of Chinese and U.S. governments, both of which had several subpages. In this case, unlike the threaded discussion forum where links to all the posts were displayed on one page, the posts in Diigo were distributed on different webpages, making it harder for learners to read all the posts.

The fact that there were more posts in Diigo than in the discussion forum suggested that Web annotation might be better at provoking thoughts and motivating participation. A possible reason would be that Web annotation allowed learners to post whenever they had any thoughts or ideas related to the specific content on the webpages. In the discussion forum, in contrast, learners had to post discussions to a separate place. Although participants tended to post more often in Diigo, posts in the discussion forum were longer. A possible reason might be that the discussion forum had more space for writing the posts. In Diigo, the sticky notes were displayed adjacent to the original texts, and the relatively small size of the sticky note makes it inconvenient to write long posts. Also, in Diigo, the content of posts was usually related to a specific part of the material, while in the discussion forum, participants were more likely to focus on the whole picture by writing longer and more summarized posts. 
Finally, when it came to the engagement, participants reported that they had more fun and were more actively engaged in the Web annotation environment. However, it was possible that the active engagement was due to the fact that the Web annotation environment was new to participants.

\section{Pedagogical Implications}

Based on the results of this study, the following pedagogical implications for practice are proposed:

First of all, this study suggests that Web annotations tools have the capacity to support online discussions. In this study, Diigo successfully supported interactions and collaborative learning efforts among learners. More specifically, Diigo made it easy for learners to locate the information on the websites and connect the learning materials to the discussion. Using the sticky notes that are positioned adjacent to the related materials, learners do not have to go back and forth to read the materials when having discussions. In this case, if the topics of online discussion are related to electronic reading materials on webpages, Web annotation tools can be used as a major or complementary tool for online discussions to support and encourage interactions among learners. In online courses, Web annotation tools can be used for learners who are geographically far from each other to communicate. The discussions on the Web annotation tools may not be limited to formal discussions initiated by the instructor. Informal discussions may also occur when learners share the Web annotations on the electronic learning materials with their classmates, which may help promoting the informal interactions among learners and enhancing a feeling of belonging.

The results of this study also indicate that different online tools afford different types of interactions. Therefore, to design a successful online learning activity, it is necessary to evaluate the delivery tool to determine its fitness in supporting the activity. Instructors need to critically evaluate the functions of the delivery tools and decide which tool can serve the learning purposes best. Web annotation would be a better tool if the topic of discussion is closely related to specific parts of electronic materials. The threaded-discussion forum is more suitable for discussion topics that require summaries and synthesis across learning materials because it provides learners with more spaces to elaborate their thoughts.

\section{Limitations and Future Research}

The low number of participants and the case study research design of the present study cause several limitations and provide new directions for future research. First, because of the low number of participants, the validity of the survey was not tested. In addition, the small sample size of participants and the qualitative design of this study make it impossible to do statistical tests to compare participants' performance in the two environments, which limits the generalization of the findings. According to the perspective of naturalistic generalization, the process of generalization should be based on similarity of settings and participants (Burke, 1997; Stake, 1990). It is important for readers to compare the settings and participants before they generalize the findings of this study. It is worth to note that the following factors may impact the generalization of this study:

First, all participants in this study were adult learners who identified themselves as intermediate or expert users of technology. In this case, it is possible that their familiarity with technology had positive impacts on their experience. Learners' technology proficiency should be considered carefully if one wants to generalize the findings of this study to other contexts. In addition, participants in this study were all doctoral students, who might had higher motivations and more advanced learning techniques than average learners. To testify the existing findings, future study needs to be conducted in different contexts with learners with different academic degree levels or varied technology proficiency levels. 
Besides generalization, the research design of this study has limitations. Instead of assigning the participants into a control group and an experimental group, this study provided them with free access to both the Web annotation tool and the threaded discussion forum, and observed how they chose the environment(s) to participate in the discussion. This design allowed us to explore the factors that affected learners' choice of discussion environments and gave us insights on the unique affordances and constraints of the two environments. The design, however, prevented us from conducting a strict comparison between the two environments. In addition, this study focused more on revealing how learners behaved and how their learning processes differed in the two environments as was suggested by the focus and types of their posts. The actual learning outcome, however, was not measured. The contributions of students had no grade value in this study, which might have impacts on students' performance. As a result, future study with an experimental design is needed to measure and compare learners' performance and learning in the two discussion environments.

\section{Conclusion}

Web annotation is a collaborative tool that allows learners to add annotations to webpages and share annotations with each other. This study examined the potential use of Web annotation as a tool to support online discussions by comparing it to a threaded discussion forum. While most of the current literature on Web annotation focuses on the impact of collaborative Web annotation tools on learning outcomes, this study explored the nature of interactions when Web annotation was used as an online discussion tool.

Although the study is exploratory in nature, it has some important contributions to the existing research on online discussion and the educational use of Web annotation tools. First, online discussions held in threaded forums have often been criticized as lack of focus or off-topic (Wu \& Hou, 2013), and researchers have been experimenting with alternative tools to enable a more focused discussion. Our study suggests that Web annotation tools have a potential to encourage discussions that are closely tied to the specific parts of the learning materials, leading to a more focused discussion. As a result, having discussions using Web annotation tools may be a good alternative for achieving certain learning goals.

Second, current research on the educational use of Web annotation tools has been centered around its impacts on learning outcomes, and little has focused on the learning processes enabled by the tools. We argue, however, examining the learning processes is important because it allows us to understand the mechanism of how learning takes place and make it possible to further explore ways to support optimal learning. The study, by comparing the nature of discussion in the threaded forum and Diigo, provides a starting point for future research to investigate the potential effects of Web annotation tools and how such tools can be adopted to enhance learning.

\section{References}

Bryceson, K. (2007). The online learning environment--A new model using social constructivism and the concept of 'Ba' as a theoretical framework. Learning Environments Research, 10(3), 189-206.

Burke, R (1997). Examining the validity structure of qualitative research. Education, 118(2), 282-292.

Cohen, J. (1992). A power primer. Psychological Bulletin, 112(1), 155-9.

Cornelius, S., Gordon, C., \& Ackland, A. (2011). Towards flexible learning for adult learners in professional contexts: An activity-focused course design. Interactive Learning Environments, 19(4), 381393.

Driver, R., Asoko, H., Leach, J., Mortimer, E., \& Scott, P. (1994). Constructing scientific knowledge in the classroom. Educational Researcher, 23(7), 5-12. 
Dillenbourg, P., \& Schneider, D. (1995). Collaborative learning and the Internet. Proceedings of International Conference on Computer-Assisted Instruction. Retrieved from http://tecfa.unige.ch/tecfa/research/CMC/colla/iccai95 1.html

Dunlosky, J., Rawson, K., Marsh, E., Nathan, M., \& Willingham, D. (2013). Improving students learning with effective learning techniques: promising directions from cognitive and educational psychology. Psychological Science in the Public Interest, 14(1), 4-58.

Gao, F. (2013). A case study of using a social annotation tool to support collaboratively learning. The Internet \& Higher Education, 17, 76-83.

Glover, I., Xu, Z., \& Hardaker, G. (2007). Online annotation--research and practices. Computers \& Education, 49(4), 1308-1320.

Huang, H. (2002). Toward constructivism for adult learners in online learning environments. British Journal of Educational Technology, 33(1), 27-37.

Hwang, W., Wang, C., \& Sharples, M. (2007). A study of multimedia annotation of web-based materials. Computers \& Education, 48(4), 680-699. doi: 10.1016/j.compedu.2005.04.020

Johnson, T. E., Archibald, T. N., \& Tenenbaum, G. (2010). Individual and team annotation effects on students' reading comprehension, critical thinking, and meta-cognitive skills. Computers in Human Behavior, 26(6), 1496-1507. doi: 10.1016/j.chb.2010.05.014

Jonassen, D. H. (1990). Thinking technology: Toward a constructivist view of instructional design. Educational Technology, 30(9), 32-34.

Kanuka, H., \& Anderson, T. (1998). Online social interchange, discord and knowledge construction. Journal of Distance Education, 13(1), 57-74.

Kappe, F., \& Maurer, H. (1994). From hypertext to active communication/information systems. Journal of Microcomputer Applications, 17, 333-344.

Koivunen, M.-R., \& Swick, R. R. (2001). Metadata based annotation infrastructure offers flexibility and extensibility for collaborative applications and beyond. Proceedings of K-CAP2001 workshop knowledge markup and semantic annotation. Retrieved 05.23.13 from http://semannot2001.aifb.unikarlsruhe.de/papers/1_annotea.pdf

Lin, C., \& Tsai, C. (2011). Applying social bookmarking to collective information searching (CIS): An analysis of behavioral pattern and peer interaction for co-exploring quality online resources. Computers in Human Behavior, 27(3), 1249-1257. doi: 10.1016/j.chb.2011.01.005

Marshall, C. (1997). Annotation: from paper books to the digital library. Proceedings of ACM digital libraries 1997. Retrieved 05.20.13 from http://www.csdl.tamu.edu/ marshall/pubs.html

Marshall, C. (1998). Toward an ecology of hypertext annotation. Proceedings of ACM hypertext 1998, 4049.

Mendenhall, A., \& Johnson, T. E. (2010). Fostering the development of critical thinking skills, and reading comprehension of undergraduates using a web 2.0 tool coupled with a learning system. Interactive Learning Environments, 18(3), 263-276. doi: 10.1080/10494820.2010.500537

Merriam, S. B., Caffarella, R. S., \& Baumgartner, L. M. (2007). Learning in adulthood: A comprehensive guide. San Francisco, CA: Jossey-Bass.

Neo, M., \& Neo, T. (2009). Engaging students in multimedia-mediated constructivist learning--students' perceptions. Educational Technology \& Society, 12(2), 254-266.

Nokelainen, P., Miettinen, M., Kurhila, J., Floréen, P., \& Tirri, H. (2005). A shared document-based annotation tool to support learner-centred collaborative learning. British Journal of Educational Technology, 36(5), 757-770. doi: 10.1111/j.1467-8535.2005.00474.x

Ovsiannikov, I. A., Arbib, M. A., \& McNeill, T. H. (1999). Annotation technology. International Journal of Human-Computer Studies, 50, 329-362. 
Pena-Shaff, J. B., \& Nicholls, C. (2004). Analyzing student interactions and meaning construction in computer bulletin board discussions. Computers \& Education, 42, 243-265.

Stake, R. E. (1990). Situational context as influence on evaluation design and use. Studies on Educational Evaluation, 16, 231-246

Su, A. Y. S., Yang, S. J. H., Hwang, W., \& Zhang, J. (2010). A web 2.0-based collaborative annotation system for enhancing knowledge sharing in collaborative learning environments. Computers \& Education, 55(2), 752-766.

Wang, Q. (2010). Using online shared workspaces to support group collaborative learning. Computers \& Education, 55(3), 1270-1276.

Wolfe, J. (2008). Annotations and the collaborative digital library: Effects of an aligned annotation interface on student argumentation and reading strategies. International Journal of Computer-Supported Collaborative Learning, 3(2), 141-164. doi: 10.1007/s11412-008-9040-x

Wu, S. Y., \& Hou, H. T. (2013). Exploring the process of planning and implementation phases in an online project-based discussion activity integrating a collaborative concept-mapping tool. The Asia-Pacific Education Researcher, 22(2), 1-7.

Yang, S. J. H., Chen, I. Y., \& Shao, N. W. Y. (2004). Ontology enabled annotation and knowledge management for collaborative learning in virtual learning community. Educational Technology \& Society, $7(4), 70-81$.

Yang, S. J. H., Zhang, J., Su, A. Y. S., \& Tsai, J. J. P. (2011). A collaborative multimedia annotation tool for enhancing knowledge sharing in CSCL. Interactive Learning Environments, 19(1), 45-62.

Yeh, S., \& Lo, J. (2009). Using online annotations to support error correction and corrective feedback. Computers \& Education, 52(4), 882-892.

\section{Appendix A. Online Discussion Environments Survey}

Q1 What do you like about having discussions in Diigo sticky notes as compared to Discussion Forum?

Q2 What do you dislike about having discussions in Diigo sticky notes as compared to Discussion Forum?

Q3 In the discussion,

I posted all my discussions in Diigo sticky notes.

I posted all my discussions in Discussion Forum.

I posted my discussion on question 1 in Diigo sticky notes and my discussions on question $2 \& 3$ in Discussion Forum.

I posted my discussion on question $1 \& 2$ in Diigo sticky notes and my discussions on question 3 in Discussion Forum.

I posted my discussion on question 1 in Diigo sticky notes and my discussions on question 2 \& 3 in Discussion Forum.

I posted my discussion on question $1 \& 2$ in Diigo sticky notes and my discussions on question 3 in Discussion Forum.

I posted my discussion on question $1 \& 3$ in Diigo sticky notes and my discussions on question 2 in Discussion Forum.

I posted my discussion on question 2 in Diigo sticky notes and my discussions on question $1 \& 3$ in Discussion Forum. 
Q4 How do features in different discussion environments lead you to make the above discussion.(Please provide a detailed explanation.)

Q5 I think Diigo sticky notes made it EASY

\begin{tabular}{|c|c|c|c|c|c|}
\hline & $\begin{array}{l}\text { Strongly Dis- } \\
\text { agree }\end{array}$ & Disagree & $\begin{array}{l}\text { Neither } \\
\text { Agree nor } \\
\text { Disagree }\end{array}$ & Agree & $\begin{array}{c}\text { Strongly } \\
\text { Agree }\end{array}$ \\
\hline $\begin{array}{l}\text { To read every- } \\
\text { one else's } \\
\text { posts. }\end{array}$ & 0 & 0 & 0 & 0 & 0 \\
\hline $\begin{array}{l}\text { To pay atten- } \\
\text { tion to specific } \\
\text { information in } \\
\text { the Web }\end{array}$ & 0 & 0 & 0 & O & $\mathrm{O}$ \\
\hline $\begin{array}{c}\text { To develop } \\
\text { new ideas } \\
\text { based on the } \\
\text { discussion. }\end{array}$ & 0 & O & 0 & O & 0 \\
\hline $\begin{array}{l}\text { To connect a } \\
\text { specific ele- } \\
\text { ment in the } \\
\text { Web to your } \\
\text { discussion. }\end{array}$ & 0 & 0 & 0 & 0 & 0 \\
\hline $\begin{array}{l}\text { To revise your } \\
\text { understanding } \\
\text { on the topics. }\end{array}$ & 0 & 0 & 0 & 0 & 0 \\
\hline $\begin{array}{l}\text { To exchange } \\
\text { ideas or opin- } \\
\text { ions with your } \\
\text { classmates }\end{array}$ & $\mathrm{O}$ & O & O & 0 & O \\
\hline
\end{tabular}


Q6 I think Discussion forum made it EASY

\begin{tabular}{|c|c|c|c|c|c|}
\hline & $\begin{array}{c}\text { Strongly Dis- } \\
\text { agree }\end{array} \mid$ & Disagree & $\begin{array}{c}\text { Neither } \\
\text { Agree nor } \\
\text { Disagree }\end{array}$ & Agree & $\begin{array}{c}\text { Strongly } \\
\text { Agree }\end{array}$ \\
\hline $\begin{array}{l}\text { To read every- } \\
\text { one else's } \\
\text { posts. }\end{array}$ & 0 & 0 & 0 & 0 & 0 \\
\hline $\begin{array}{l}\text { To pay atten- } \\
\text { tion to specific } \\
\text { information in } \\
\text { the Web }\end{array}$ & 0 & $\mathrm{O}$ & 0 & 0 & $\mathrm{O}$ \\
\hline $\begin{array}{l}\text { To connect a } \\
\text { specific ele- } \\
\text { ment in the } \\
\text { Web to your } \\
\text { discussion. }\end{array}$ & 0 & 0 & 0 & $\mathrm{O}$ & 0 \\
\hline $\begin{array}{l}\text { To revise your } \\
\text { understanding } \\
\text { on the topics. }\end{array}$ & 0 & 0 & 0 & 0 & 0 \\
\hline $\begin{array}{c}\text { To exchange } \\
\text { ideas or opin- } \\
\text { ions with your } \\
\text { classmates }\end{array}$ & O & $\mathrm{O}$ & O & O & $\mathrm{O}$ \\
\hline
\end{tabular}

Q7 What specific features in the discussion environments lead you to think so?(Please explain your ratings above.)

Q8 What specific features in the discussion environments lead you to think so?(Please explain your ratings above.)

Q9 The environment in Diigo sticky notes

\begin{tabular}{|c|c|c|c|c|c|}
\hline & $\begin{array}{c}\text { Strongly Dis- } \\
\text { agree }\end{array}$ & Disagree & $\begin{array}{c}\text { Neither } \\
\text { Agree nor } \\
\text { Disagree }\end{array}$ & Agree & $\begin{array}{c}\text { Strongly } \\
\text { Agree }\end{array}$ \\
\hline $\begin{array}{c}\text { made me } \\
\text { more willing } \\
\text { to participate } \\
\text { in dissuasion. }\end{array}$ & 0 & 0 & 0 & 0 & 0 \\
$\begin{array}{c}\text { was fun. } \\
\text { was actively } \\
\text { engaged }\end{array}$ & 0 & 0 & 0 & 0 & 0 \\
\hline
\end{tabular}


Q10 The environment in Discussion forum.

\begin{tabular}{|c|c|c|c|c|c|}
\hline & $\begin{array}{c}\text { Strongly Dis- } \\
\text { agree }\end{array}$ & Disagree & $\begin{array}{c}\text { Neither } \\
\text { Agree nor } \\
\text { Disagree }\end{array}$ & Agree & $\begin{array}{c}\text { Strongly } \\
\text { Agree }\end{array}$ \\
\hline $\begin{array}{c}\text { made me } \\
\text { more willing } \\
\text { to participate } \\
\text { in dissuasion. }\end{array}$ & 0 & 0 & 0 & 0 & 0 \\
$\begin{array}{c}\text { was fun. } \\
\text { was actively } \\
\text { engaged }\end{array}$ & 0 & 0 & 0 & 0 & 0 \\
\hline
\end{tabular}

Q11 What specific features in the discussion environments lead you to think so?(Please explain your ratings above.)

Q12 What suggestions do you have to promote Diigo sticky notes as a discussion environment?

Q13 You are

a female.

O a male.

Q14 Your age is

O 20 and below

O $20-25$

O $26-30$

O $31-35$

O $36-40$

O $41-45$

O 45 and above

Q15 As a technology user, you classify yourself as

O Beginner.

O Intermediate.

O Expert. 


\section{Biographies}

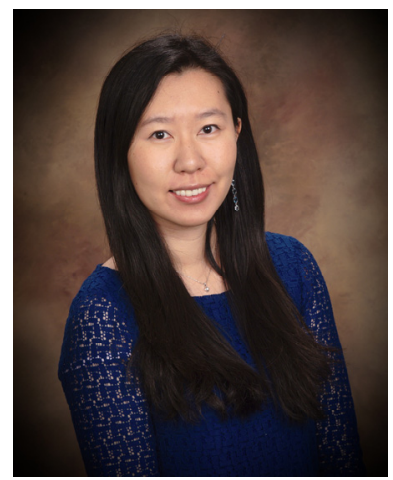

Yanyan Sun is a Ph.D. candidate in Instructional Technology program at Ohio University. She received her master degree in foreign and second language acquisition from the Ohio State University and had several years of experience in teaching Chinese as a foreign language. Her research interests include computer-assisted language teaching and learning, educational applications of Web 2.0 technology, mobile learning, social media and the integration of technology in curriculum development. She is also involved in studies of using social media technology to improve students' performance in foreign/second language teaching and learning practice.

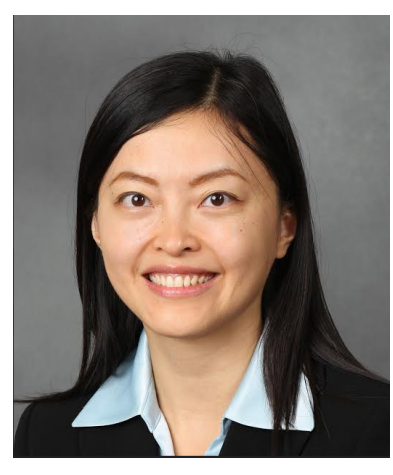

Dr. Fei Gao is an Assistant Professor of Learning Design at Bowling Green State University, USA. She holds a Ph.D. in Educational Psychology and Educational Technology from Michigan State University. Her research focuses on designing technology-enhanced learning environments, computer-mediated communication, e-learning, social media and informal learning. She has presented at numerous national and international conferences, and her work has been published in highquality peer-reviewed journals, including British Journal of Educational Technology, The Internet and Higher Education, Journal of Interactive Learning Research, and Journal of Educational Computing Research. 